\title{
Dynamic forest fire risk evaluation in Poland
}

\author{
Ryszard Szczygiet, Mirosław Kwiatkowski, Bartłomiej Kołakowski 凶, Józef Piwnicki \\ Forest Research Institute, Laboratory of Forest Fire Protection, Braci Leśnej 3, Sękocin Stary, 05-090 Raszyn, Poland, \\ e-mail: b.kolakowski@ibles.waw.pl
}

\begin{abstract}
The weather conditions determine the dynamic forest fire risk. In Poland, the dynamic forest fire risk is calculated using a method elaborated at the Forest Research Institute. The forest fire risk degree (4-level scale) is calculated every day at 9:00 am and at 1:00 pm during the fire season (1.03 till 30.09) for 60 prognostic zones selected on the basis of stand and climatic conditions. $97 \%$ of all annual forest fires occur during the fire season. Surface fires are a significant part of the fires $(90 \%)$ and occur in forest stands where pine is the dominant species. The purpose of the research was to prepare a new method of forecasting forest fire risk, which would enable a more precise method of evaluation of the risk of an outbreak of fire in relation to the existing and forecast meteorological conditions in forests. The results obtained during testing of this method indicate a high accuracy in forecasting fire risk and a satisfactory precision of formulae for calculating moisture content of pine litter.

The assumptions of the new method included:

- possibility of determining the actual risk of fire for the given area, being the average for all measurement points located on the terrain equally those in which the moisture content measurement of litter has not been performed,

- possibility of forecasting the risk of forest fire for the afternoon in the morning hours of the given day,

- possibility of forecasting fire risk for the following day,

- forecasting moisture content of litter for the afternoon and of the given day and for the following day,

- drawing up a method enabling limitation of operational costs of fire prevention system.
\end{abstract}

\section{KeY WORDS}

forest fire risk degree, dynamic forest risk, pine litter moisture content, method of forecasting forest fire risk

\section{INTRODUCTION}

The high forest fire risk in Poland is the result of abiotic, biotic and anthropogenic threats existing in the country. The abiotic threats are mainly driven by the geographical position of Poland - situated exactly where the continental and marine climates clash. The weather anomalies connected with this specific location of Po- land lead to the more frequent occurrence of extreme air temperatures, high precipitations and strong winds. The majority of Polish forest land is located on poor, sandy soils with high groundwater permeability. The negative influence of the mass invasion of insect pests and infectious diseases are the biotic threats influencing the Polish forests and determining fire risk. The most decisive role (among the biotic factors) regarding fire risk 
is played by the forest habitat types that exist in Poland. The prevailing coniferous species in Poland are particularly prone to fires - with mostly scotch pine (Pinus sylvestris L.) as the dominant species. The growing forest accessibility and its penetration by people increase the probability of the occurrence of a high energetic stimulus capable of initiating fires. This situation corresponds in particular with forest urban interface, where a high exploration of forests results in an increase in fire risk and the number of fires.

According to the Joint Research Centre (located in Ispra, Italy), in the years 2006-2015, Poland was classified in the third position (after Portugal and Spain) when counting the average annual number of forest fires (8260), and in ninth position, when calculating the burnt area (3745 ha). Regarding the average burnt area of a single forest fire, which can indicate the efficiency of the forest fire protection system, Poland sits in the eighteenth position (average burnt area around $0.45 \mathrm{ha}$ ). Forest fire risk evaluations along with adequate organization form the basis of the efficiency of the fire protection system. Permanent increase of fire risk, the effect of which is the increasing number of fires and area burnt and also the increasing operating costs of the fire prevention system were the stimuli to undertake research intended to limit fire losses. The possibility of reducing losses, apart from prevention activities, should be sought primarily in limiting the surface area burnt as a result of fires. This objective may be achieved by optimising fire extinguishing activities. The basis for this is accurate forecasting of fire risk of forest based on meteorological and physical conditions prevailing in the forest. This information enables specification of the required state of operational readiness of the services responsible for forest fire prevention.

\section{Material AND MEthods}

The basis for evaluation of conditions of the occurrence of fires in forests were the data of National Forests from the years 2002-2008. This analysis equally included the occurrence of fires in relation to stand conditions, types of fires, temporal analysis of occurrence in particular months and times of day, as also the occurrence of fires in relation to meteorological conditions. In the analysis of occurrence of fires in relation to meteorological conditions and moisture of pine litter, 25,000 fires were con- sidered. It consisted primarily of evaluation of the number of fires in relation to the values of these parameters.

Figure 1 presents an example schedule of frequency of occurrence of fires depending on the moisture of pine litter together with the expected schedule and the strength of the connection between the observed and expected values expressed as a value of the coefficient of determination and $\mathrm{R} 2$.

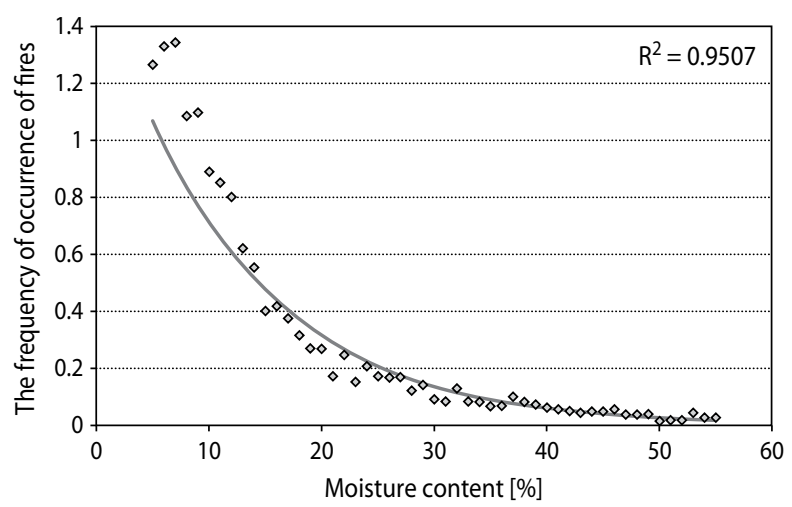

Figure 1. Frequency of occurrence of fires after the hour 13.00 in relation to the moisture content of pine litter at 13.00

All analyses of occurrences of fires in relation to the most crucial parameters were performed using the reverse step multiple regression method. On this basis, the polynomials enabling establishment of fire risk for particular points were calculated. In order to standardise the principles of defining the degree of fire risk from the values of polynomials, particular formulae were converted in such a manner that the specified degree of fire risk from the value of polynomial of particular formulae were converted in such a way that the specified range of polynomial values always corresponded to the same degree of fire risk. Depending on the values thus calculated for the polynomial, it is possible to establish the degree of fire risk for the given point.

\section{REsults}

The basis for determining forest fire risk is:

- moisture content of the top-layer of pine litter Pinus sylvestris $L$. (WS) - this parameter determines the possibility of fire initiation, 


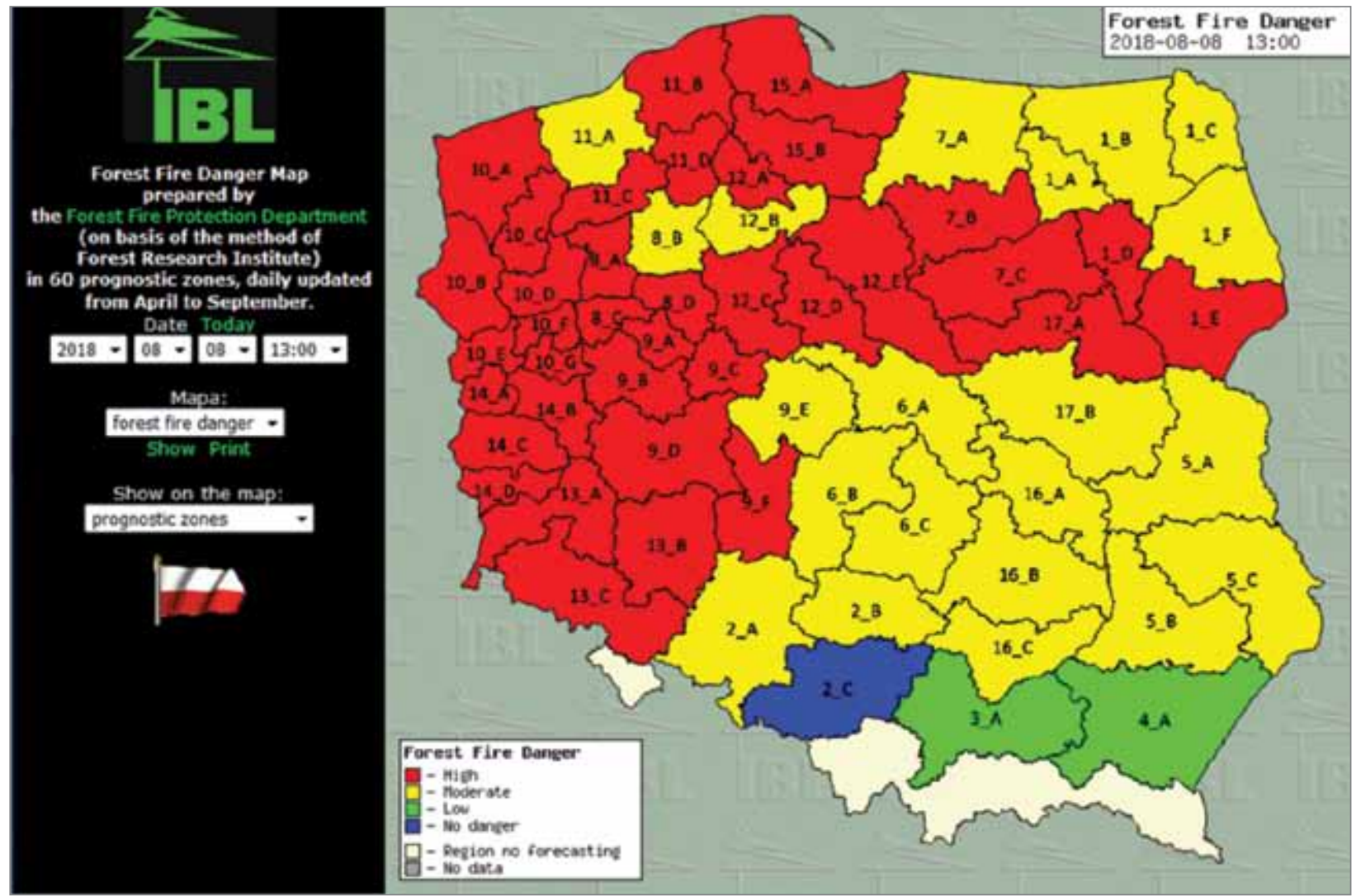

Figure 2. Forest fire risk degree map

- temperature (TP) and relative air humidity (WP) measured at a height of $0.5 \mathrm{~m}$,

- daily sum of precipitation (OP).

The method calculates the forest fire risk degree using the measured data and enables to forecast risk $24 \mathrm{~h}$ ahead. The current forest fire risk degree is determined from the basis of data derived from 146 meteorological measuring points, located in a way to reflect the impact of forest stand on the local climate conditions. The moisture content of the top-layer of pine litter is measured by using a dry-weight scale, specially programmed, which automatically transfers the results to a dedicated IT system.

The forecasted forest fire risk degree is calculated using forecasted meteorological parameters derived from numerical weather models and forecasted moisture content of pine litter (calculated using dedicated equations). Figure 2 presents an example of the forest fire risk degree map on an area of 60 prognostic zones from 8 August 2018.
Both current and forecasted forest fire risk degree is calculated using the polynomial values reflecting the possibility of fire occurrence. The polynomials were elaborated on the basis of detailed statistical analyses regarding fire occurrence in relation to moisture content and other meteorological parameters. Examples of polynomials, elaborated using a reverse step multiple regression method for a meteorological measuring point where moisture content of pine litter is measured, are presented below (polynomial 1 and 2).

The fire risk polynomial for the meteorological measuring point at 9:00 a.m.

$$
\begin{aligned}
& \text { Wiel_prog_09 }=0.9608-2.1348 \cdot \mathrm{e}^{\left(0.05 \cdot T P_{-} 09\right)}+ \\
& \begin{aligned}
+241.5402 \cdot & \mathrm{e}^{(-0.05 \cdot \mathrm{WP} 09)}-4.4492 \cdot \mathrm{e}^{\left(-0.2 \cdot \text { OP}_{-} 09\right)}+ \\
& +64.3136 \cdot \mathrm{e}^{\left(-0.1 \cdot \mathrm{WS} \_09\right)}
\end{aligned}
\end{aligned}
$$

The fire risk polynomial for the meteorological measuring point at 1:00 p.m. 
Wiel_prog $13=14.8636-15.9004 \cdot \mathrm{e}^{\left(0.05 \cdot \mathrm{TP} \_09\right)}+$ $+203.3911 \cdot \mathrm{e}^{\left(-0.05 \cdot \mathrm{WP}_{-} 09\right)}-127.2755 \cdot \mathrm{e}^{\left(-0.1 \cdot \mathrm{WS}_{-} 09\right)}+$

$$
+1.3053 \cdot \mathrm{e}^{\left(0.1 \cdot \mathrm{TP}_{-} 13\right)}+791.2685 \cdot \mathrm{e}^{\left(-0.1 \cdot \mathrm{WP}_{-} 13\right)}
$$

where:

TP_09 - air temperature at 9:00 a.m.,

TP_13 - air temperature at 1:00 p.m.,

WP_09 - relative air humidity at 9:00 a.m.,

WP_13 - relative air humidity at 1:00 p.m.,

OP 09 - daily precipitation sum at 9:00 a.m.,

WS_09 - litter moisture content at 9:00 a.m.,

WS_13 - litter moisture content at 1:00 p.m.,

e $\quad-$ Euler number $(=2.718281828459)$.

In every $s$

In every single case, the correlation for the elaborated dependence was poor or average.

The correlation strength was recognized as satisfactory due to the fact that in Poland, fires caused by natural factors barely occur and their occurrence is determined by favourable weather and heat stimulus linked with an aware or not aware human act. The highest correlation values were found in the case of polynomials calculated for 1:00 p.m. - when the fire risk is at the highest level. The key value for forest risk calculation is the moisture content of pine litter. That was the reason to aim for the best verifiability of forest fire risk forecast during the elaboration of the equations - keeping the level of acceptable error at $20 \%$ of real value for the real values of moisture content of pine litter not higher than $40 \%$. The above assumption guarantees the proper calculation of moisture content of pine litter in its range where fire ignition is possible (flammability threshold of moisture content for pine litter is $30 \%$ ) including the possibility of diversification of moisture content for the area of the whole prognostic zone. Reverse step multiple regression was used here again to estimate the dependence between the moisture content of pine litter in the afternoon and on the next day to its actual value. The current and forecasted values of the meteorological parameters together with the current moisture content of pine litter and its average value within the last 4 days were included in the analyses. The higher correlation was obtained for the moisture content of pine litter. For the forecast at 9:00 a.m. of the next day, the correlation

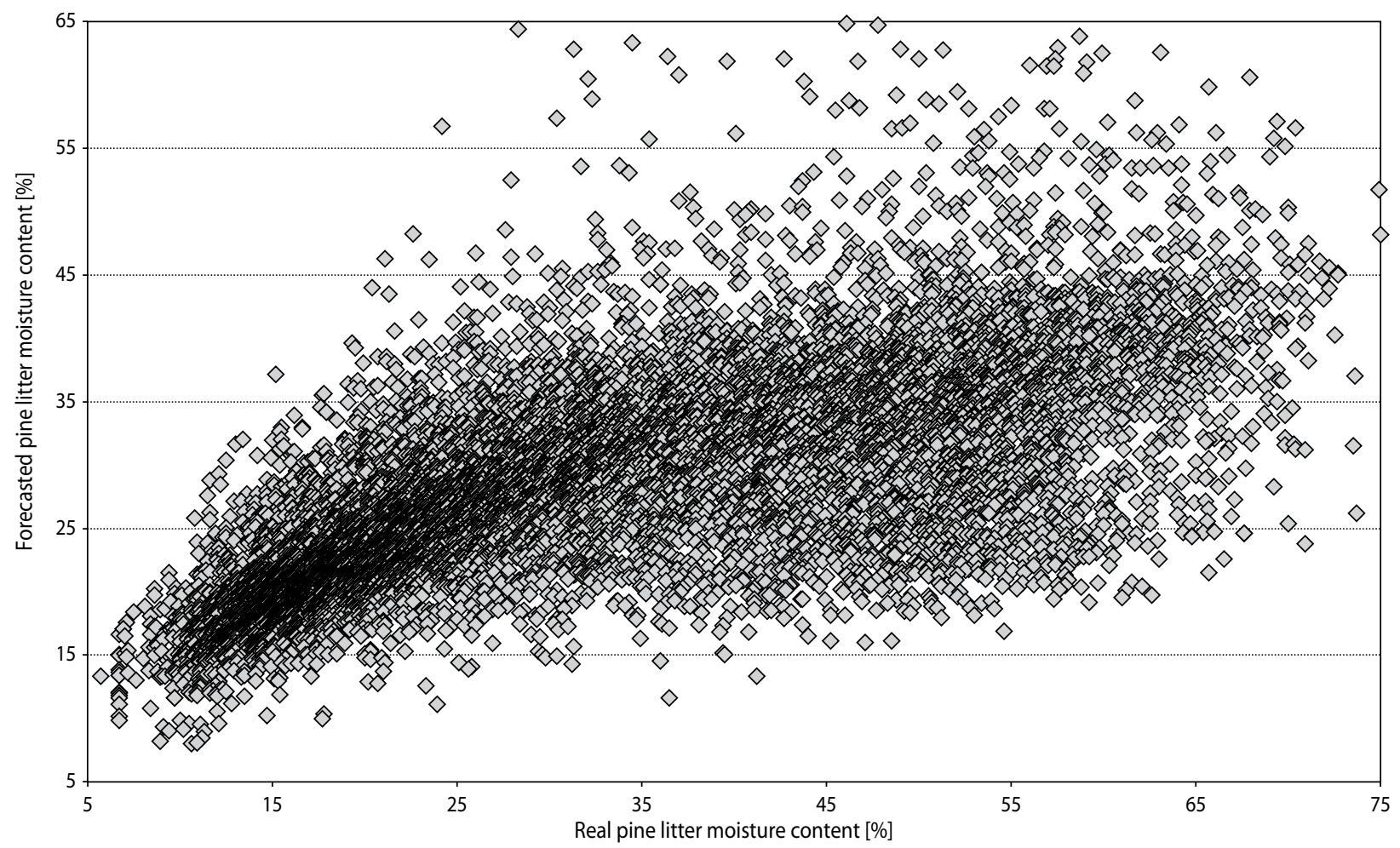

Figure 3. The distribution of the forecasted pine litter moisture content at 9:00 a.m. of the next day 
was very strong, and for the forecast at 1:00 p.m. of the present day, the correlation was almost perfect. The examples are presented below (equations 3 and 4).

The moisture content of pine litter forecasted at 9:00 a.m. of the next day:

$$
\begin{gathered}
\text { wilg_1_09_lin }=-3.9388+0,0834 \cdot \mathrm{TP} 09+ \\
\quad+0.0931 \cdot \mathrm{OP} \_09+0.331 \cdot \mathrm{WS} \_09+ \\
+0.0531 \cdot \mathrm{WS} 13 \_1+0.0411 \cdot \mathrm{WS} \text {-09_A1 }+ \\
\quad+0.3212 \cdot \mathrm{TP} 0 \_13+0.0613 \cdot \mathrm{WP} 0 \_13+ \\
\quad+1.5545 \cdot \mathrm{OP} 0 \_13+0.5737 \cdot \mathrm{Z} 0 \_13+ \\
\quad-0.324 \cdot \mathrm{VW} 0 \_13-0.2801 \cdot \mathrm{TP} 1 \_09+ \\
\quad+0.1344 \cdot \mathrm{WP} 109+0.3395 \cdot \mathrm{VW} 1 \_09
\end{gathered}
$$

The moisture content of pine litter at 1:00 p.m.:

$$
\begin{gathered}
\text { wilg_0_13_lin }=1.1681 \cdot[(-3.0131+ \\
+0.0366 \cdot \mathrm{WP} \_09+0.17765 \cdot \mathrm{OP} \_9+ \\
+0.62244 \cdot \mathrm{WS} \_9-0.0236 \cdot \mathrm{WS} \_09 \_1+ \\
+0.1024 \cdot \mathrm{WS} \_13 \_1-0.0586 \cdot \mathrm{TP} \_-13+ \\
+0.07092 \cdot \mathrm{WP} 0 \_13+1.16606 \cdot \mathrm{OP0} 013+ \\
\left.\left.0.10282 \cdot \mathrm{Z} 0 \_13\right)^{0.9413}\right]
\end{gathered}
$$

where:

TP_09 - air temperature at 9:00 a.m.,

WP_09 - relative air humidity at 9:00 a.m.,

OP_09 - daily sum of precipitation at 9:00 a.m.,

WS_09-moisture content of pine litter at 9:00 a.m.,

WS_09_1 - moisture content of pine litter at 9:00 a.m. of the previous day,

WS_13_1 - moisture content of pine litter at 1:00 p.m. of the previous day,

TP0_13 - forecasted air temperature at 1:00 p.m.,

WP0_13 - forecasted relative air humidity at 1:00 p.m.,

OP0_13 - forecasted precipitation sum at 1:00 p.m.,

VW0_13 - forecasted wind speed at 1:00 p.m.,

WP_13 - relative air humidity at 1:00 p.m.,

WS_09_A1 - average value of the moisture content of pine litter within the previous 4 days,

Z0_13 - forecasted cloudiness at 1:00 p.m.,

TP1_09 - forecasted air temperature at 9:00 a.m. of the next day,

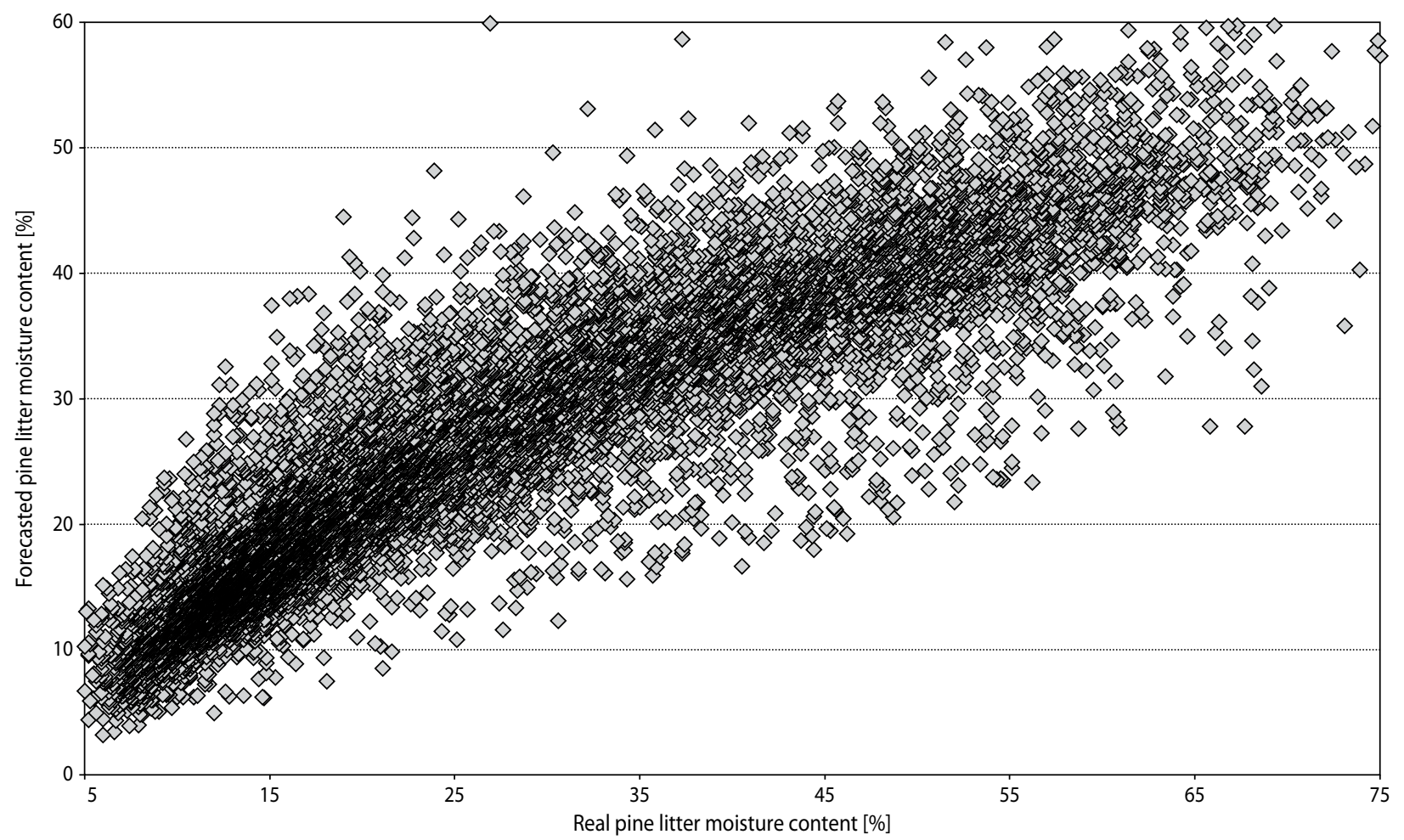

Figure 4. The distribution of the pine litter moisture content at 1:00 p.m. 
WP1_09 - forecasted relative air humidity at 9:00 a.m. of the next day,

VW1_09 - forecasted wind speed at 9:00 a.m. of the next day.

The effectiveness of the elaborated equations is very high (acceptable error threshold is $20 \%$ of the real value). An effectiveness of $67.3 \%$ was obtained for the morning hours of the next day, and for the afternoon hours, the effectiveness was $71.4 \%$. The distribution of the real and forecasted values is presented in Figures 3 and 4 .
The presented results obtained during the testing of this method indicate great accuracy in forecasting forest fire risk and satisfactory accuracy of formulae enabling the calculation of litter moisture content. As a result of the work, a forecasting method was successfully established enabling the precise determination of fire risk in forests. Such a solution may bring about significant limitation of forest fire prevention operating costs and facilitate the organisational work of the services responsible for forest fire protection. 